\title{
The Prevalence of Posttraumatic Stress Disorder Following Childbirth and its Predictors in Iranian Women
}

\author{
Roya Ahmadnejad ${ }^{1}$, Jamileh Malakouti ${ }^{2,}{ }^{,}$, Mojgan Mirghafourvand ${ }^{3}$ and Azizeh Farshbaf Khalili (iD) ${ }^{4}$ \\ ${ }^{1}$ Student Research Committee, Department of Midwifery, Faculty of Nursing and Midwifery, Tabriz University of Medical Sciences, Tabriz, Iran \\ ${ }^{2}$ Department of Nursing and Midwifery, Faculty of Nursing and Midwifery, Tabriz University of Medical Sciences, Tabriz, Iran \\ ${ }^{3}$ Social Determinants of Health Research Center, Tabriz University of Medical sciences, Tabriz, Iran \\ ${ }^{4}$ Aging Research Institute, Physical Medicine and Rehabilitation Research Center, Tabriz University of Medical Sciences, Tabriz, Iran \\ "Corresponding author: Department of Nursing and Midwifery, Faculty of Nursing and Midwifery, Tabriz University of Medical Sciences, Tabriz, Iran. Tel: +98-9144023216, Fax: \\ +98-4134796969, Email: hajmalakouti@gmail.com
}

Received 2020 July 08; Revised 2020 August 10; Accepted 2020 August 20.

\begin{abstract}
Objectives: The present study aimed at evaluating the prevalence of posttraumatic stress disorder (PTSD) following childbirth and its sociodemographic and obstetrics predictors.

Methods: The current cross sectional study was conducted from April to November 2017 by the random sampling method on 365 women aged 18 - 35 years whose last childbirth occurred within 38 - 42 weeks of gestation and gave birth 10 - 16 weeks before the initiation of the study, in Baneh City, Kurdistan Province, Iran. The research tools included a sociodemographic and obstetrics characteristics questionnaire and a checklist of PTSD for DSM-IV. For data analysis, independent $t$-test, one-way ANOVA, and multiple linear regression with backward stepwise selection were employed.

Results: The prevalence of PTSD following childbirth was 47.7\%. The mean \pm standard deviation of PTSD following childbirth was 13.6 \pm 10.9 , out of the attainable score of 0 - 51 . The variables, including income status, number of children, desired route of delivery, and the type of recent delivery, were identified as predictors and accounted for $34 \%$ of the variance of PTSD adjusted for other variables. Conclusions: Considering the high prevalence of PTSD following childbirth, to improve the childbirth experience, well-adjusted interventions should be planned to prevent PTSD after delivery.
\end{abstract}

Keywords: Psychological Trauma During Childbirth, Prevalence, Posttraumatic Stress Disorder, Predictors

\section{Background}

Childbirth may cause intense provocation of emotions and feelings and even result in psychological symptoms in some women due to the experience of a traumatic situation (1). Typically, it is expected that the childbirth process proceeds physiologically and is accompanied by a good beginning for playing the maternal role (2). In different studies, childbirth is considered a traumatic event, afflicting about 1.5 - $6 \%$ of women with posttraumatic stress disorder (PTSD) following childbirth. The childbirth trauma involves traumatic experiences occurring at any stage of childbirth (3). PTSD is an experience of a harmful event associated with the risk of mortality or serious harm or a threat to the physical integrity of self or others. Its symptoms include a wide range of responses, such as mental reexperiencing of the event (e.g., interfering thoughts, nightmares, and feelings involving recurrence of the event), avoiding event residuals, and arousal symptoms (e.g., irritability, anger, concentration and sleep disorders, and hy- pervigilance). The symptoms are expected to last for at least one month (4). Alteration in mood and behavior, impairments in mother's social dysfunction and adverse effects on relationships with spouse (sexual function disorder, blaming spouse due to the events of childbirth, conflict, etc.) are among the implications of PTSD following childbirth (5).

PTSD after childbirth is associated with poor motherchild relationship. Furthermore, it severely affects cognitive development and delays emotional and cognitive growth in children (6). It can even increase the risk of child mortality (7). Such women are more prone to experience stress (73\%), anxiety (64\%), and postpartum depression (810). The prevalence of PTSD after childbirth varies regionally. It compromises 1 - 3\% of total childbirths in most European countries (England, Sweden, Germany, Italy) (5-11), $5.9 \%$ in Nigeria (12), 8 - 9\% in Canada and the US $(13,14)$, and up to $13 \%$ in France (15). In Iranian settings, it is reported 17.2 - 32\% in two studies conducted in Zahedan $(16,17)$, up 
to $36.7 \%$ in Bushehr (18), and 39\% in Southern cities of West Azerbaijan Province (19), all higher than the global rate.

Ayers et al., examined PTSD after childbirth among 218 women from 6 to 24 weeks of childbirth; the observed prevalence was $2.8 \%$. However, it decreased to $1.5 \%$ six months after childbirth (11). Some other investigations examined the risk factors of PTSD following childbirth. The personality, the extent of obstetrical interventions, extreme emotional reactions toward childbirth, conflicts with hospital staff, lack of social support, a history of psychological problems, anxiety, loss of control, lack of support from the spouse (20), pre-childbirth depression, and life-threatening feelings, (21) were some of the risk factors.

\section{Objectives}

Given the adverse implications of PTSD after childbirth $(20,21)$ and its high prevalence in Iran (19), as well as different statistics reported from different regions of Iran (17 - 39\%), the current study, conducted in a culturally diverse geographical area in Iran, aimed at evaluating the prevalence of PTSD and determining its sociodemographic and obstetrical predictors. The study results may help women's healthcare providers, especially the midwives, design precise interventions to promote the psychological health of women during the postpartum period.

\section{Methods}

\subsection{Study Design and Participants}

The present cross-sectional study was performed from April to November 2017 on 365 postpartum women referring to health centers with childbirth 10 - 16 weeks before the study onset in Baneh City, Kurdistan Province, Iran.

The inclusion criteria were: (1) age 18 -35 years; (2) childbirth in 38 - 42 weeks of gestation; (3) initiation of sexual intercourse within the past month; (4) delivering a singleton baby; (5) being in 10 - 16 weeks of childbirth; and (6) being literate. The exclusion criteria were: (1) having a child with known abnormalities; (2) any acute or chronic disease during the pregnancy; (3) marital divorce (emotional divorce or complete divorce); (4) a history of infertility before the recent pregnancy; (5) death of the child after born for any reason; (6) death of one of the first-degree relatives; (7) history of a psychotic disease or any acute or chronic disease based on patient expression or medical records; and (8) delivery by an emergency cesarean section.

\subsection{Sample Size}

The sample size was determined 365 according to the study by Vizeh et al. (19) on PTSD following childbirth in Iran, considering $\mathrm{P}=39 \%, \mathrm{z}=1.96$, and $\mathrm{d}=0.05$, using the sample proportion formula.

\subsection{Sampling}

The study was approved by the Ethics Committee of Tabriz University of Medical Sciences (ethical code: IR.TBZMED.REC.1395.1293). Samples were randomly selected from Baneh health centers. There were four health centers and six subcenters; according to records available in each center (the number of women giving birth), the effective sample size was determined for each (considering the total sample size of 365). The list of women giving birth in each center was provided. The subjects were arranged based on numbers in the list for random selection and entered into the study if they met the inclusion criteria. However, if they did not meet the inclusion criteria, were not available, or did not want to participate, the next case was randomly selected. First of all, the samples were evaluated in terms of inclusion and exclusion criteria. If they qualified, the research objective and procedure were explained to them, and they were also assured about the confidentiality of their information. Informed consent was obtained from interested subjects. The current study was conducted on 365 eligible postpartum women within 10 - 16 weeks of childbirth; they completed the sociodemographic and obstetrics characteristics questionnaire and the PTSD symptom scale I (PSS-I). Since the vaccination of children is performed only in health centers, almost all Iranian women refer to these places after delivery and have medical records.

\subsection{Data Collection Instruments}

The data collection tools included sociodemographic and obstetrics characteristics questionnaires as well as PSSI.

The sociodemographic characteristics questionnaire included items on woman and spouse's age, level of education, occupational status, and income level. The obstetrics characteristics questionnaire included information about the desired route of delivery, type of recent delivery, gravidity, parity, number of live children, intended pregnancy in woman and spouse, place of childbirth, birth attendant, problems and complications following childbirth, pregnancy complications, and history of hospitalization during pregnancy.

PSS-I includes 17 items covering all criteria of the 4th diagnostic and statistical manual of psychological disorders (DSM-IV) to diagnose PTSD. It classifies the intensity of 
symptoms based on a Likert scale. The symptoms of PSTD after childbirth include re-experience (four items), avoidance (seven items), and arousal symptoms (six items). If one or more re-experience symptoms, three or more avoidance symptoms, and two or more arousal symptoms are present, it is diagnosed as PTSD. Total scores range from 0 to 51. There is no cut-off point for this questionnaire (22). Mirzamani et al. studied the psychometric properties of the Persian version of PSS-I in Iranian patients with PTSD. The Cronbach alpha of the Iranian version was reported 0.88 , and the kappa-coefficient calculated by the test-retest method was 1 (23).

The questionnaires were completed by the participants, and related instructions were given by the researcher to each participant. Problems with the completion of questionnaires were resolved by the researcher by providing explanations via interview. For confidentiality of information, the questionnaires used anonymous, and a code was allocated to each.

Content and face validity were utilized to demonstrate the validity of sociodemographic and obstetrics characteristics. For this purpose, the questionnaires were provided to 10 faculty members, and then, the necessary modifications were made to the items according to their feedback and comments. Moreover, by performing pretest and posttest on 30 participants within a two-week interval, the reliability of PSS-I was determined in terms of replicability and internal consistency (Cronbach alpha coefficient). The Cronbach alpha of the instrument was 0.95, and ICC (95\% confidence interval) was 0.94 (0.91 - 0.97).

\subsection{Data Analysis}

The data were analyzed with SPSS version 21. For sociodemographic and obstetrics characteristics, descriptive statistics, including frequency, percentage, mean, and standard deviation (SD), were used. Data normality was examined by skewness and kurtosis. To determine the relationship between PTSD and its dimensions and sociodemographic and obstetrics characteristics, the independent ttest and one-way ANOVA were utilized in bivariate analysis. To control the confounding variables and estimate the magnitude effect of independent variables (i.e., sociodemographic and obstetrics variables) on the dependent variable (PTSD following childbirth), multiple linear regression with backward stepwise selection was implemented. The independent variables with P-values less than 0.1 in the bivariate test were entered into the model. Before multivariate analysis, regression presumptions, including data normality, homogeneity of data variance, collinearity of outlier data, and data independence, were investigated. $\mathrm{P}<0.05$ was considered as the level of significance.

\section{Results}

The present study was performed from April to November 2017. From the subjects with medical records in health centers experiencing their 10 - 16 weeks of the postpartum period, 526 were selected based on the eligibility criteria. Finally, 365 eligible women participated in the study, and the participation rate was $69 \%$. The mean \pm SD age of women was $28.0 \pm 4.3$, and that of the spouse was $32.9 \pm 5.5$ years. About half of the women (46.6\%) and their spouses (45.7\%) had high school diploma degree. Most of the participants (94.5\%) were housewives, and over half of them (56\%) reported a sufficient monthly income (Table 1 ).

Only $0.5 \%$ reported a history of infertility before this pregnancy. Most of the pregnancies were intended for both the woman (73.5\%) and spouse (75.1\%). The mean \pm SD gravidity was $1.9 \pm 1.0$. The mean \pm SD number of live children was $1.8 \pm 0.9$, and parity was $1.8 \pm 0.9$.

More than two-thirds of women (67.6\%) desired a vaginal delivery; however, only more than half of the childbirths (59.9\%) were vaginal. More than half of the women (51.5\%) experienced their childbirth in state hospitals, $50.4 \%$ performed by obstetricians. Prenatal care was provided more than eight times for most pregnant women (64.7\%) (Table 2).

The mean \pm SD score of PTSD was $13.6 \pm 10.9$ out of the range of 0 - 51. The mean \pm SD score of re-experiencing, avoidance, and arousal symptoms was $3.5 \pm 3.1,5.1 \pm 4.9$, and $4.9 \pm 3.4$ within the range of $0-18$, respectively (Table 3). Based on the percentage, re-experiencing symptoms had the highest score, while the avoidance symptoms had the lowest. According to the results obtained from the selfreport questionnaire, the prevalence of PTSD in postpartum women was $47.7 \%$ in the current study (

The relationship between sociodemographic and obstetrics characteristics and PTSD following childbirth are provided in Tables 1 and 2 using independent $t$-test and one-way ANOVA. In terms of sociodemographic characteristics, only monthly income had a relationship with the total score of PTSD. The mean \pm SD score of PTSD was 16.8 \pm 7.9 in women with inadequate income, significantly different from those of the others $(P=0.005)$ (Table 1$)$. Regarding obstetrics characteristics, a significant relationship was observed between gravidity $(\mathrm{P}=0.039)$, parity $(\mathrm{P}=$ 0.027), number of children $(\mathrm{P}=0.033)$, intended pregnancy in woman $(\mathrm{P}=0.002)$ and spouse $(\mathrm{P}=0.003)$, desired route of delivery $(\mathrm{P}=0.001)$, type of recent delivery $(\mathrm{P}=0.008)$ and the total score of PTSD (Table 2). Therefore, the highest mean \pm SD score of PTSD was found among women in 2nd or 3rd gravidity (14.9 \pm 12.1$)$, 2nd or 3rd parity (15.1 \pm 11.9), those with 2 - 3 children (15.9 \pm 12.5$)$, unintended pregnancy for themselves and spouses (16.5 \pm 11.0$)$, cesarean 


\begin{tabular}{|c|c|c|c|}
\hline Demographic Characteristic & No. (\%) & PTSD, Mean \pm SD & P-Value \\
\hline Age, $y$ & & & $0.784^{\mathrm{b}}$ \\
\hline$<20$ & $23(6.3)$ & $14.6 \pm 11.2$ & \\
\hline $25-21$ & $93(25.5)$ & $12.6 \pm 10.2$ & \\
\hline $30-26$ & $135(37.0)$ & $13.7 \pm 10.9$ & \\
\hline $30<$ & $114(31.2)$ & $14.04 \pm 11.5$ & \\
\hline Age of spouse, $y$ & & & $0.345^{b}$ \\
\hline $30-20$ & $134(36.7)$ & $12.7 \pm 10.8$ & \\
\hline $40-31$ & $197(54.0)$ & $13.8 \pm 11.03$ & \\
\hline$\geq 41$ & $34(9.3)$ & $15.7 \pm 10.7$ & \\
\hline Employment status & & & $0.781^{c}$ \\
\hline Housewife & $344(94.5)$ & $13.5 \pm 10.9$ & \\
\hline Employed & $20(5.5)$ & $9.8 \pm 7.9$ & \\
\hline Income & & & $0.005^{b}$ \\
\hline Inadequate & $72(19.9)$ & $16.8 \pm 7.9$ & \\
\hline Relatively adequate & $203(56.1)$ & $12.4 \pm 10.4$ & $0.006^{A, B}$ \\
\hline Adequate & $87(24.0)$ & $13.0 \pm 12.1$ & $0.004^{A, C}$ \\
\hline Level of education & & & $0.242^{\mathrm{b}}$ \\
\hline Primary school & $69(18.9)$ & $13.3 \pm 9.8$ & \\
\hline Secondary school & $59(16.2)$ & $15.4 \pm 12.2$ & \\
\hline High school diploma & $155(42.6)$ & $14.1 \pm 11.3$ & \\
\hline University degree & $81(22.3)$ & $10.5 \pm 9.7$ & \\
\hline Spouse's level of education & & & $0.280^{\mathrm{b}}$ \\
\hline Illiterate & $11(3.0)$ & $2.2 \pm 1.1$ & \\
\hline Below high school diploma & $99(27.3)$ & $14.3 \pm 10.9$ & \\
\hline diploma & $166(45.7)$ & $14.02 \pm 11.6$ & \\
\hline University degree & $87(24.0)$ & $11.7 \pm 9.3$ & \\
\hline Employment status of spouse ${ }^{d}$ & & & $0.124^{\mathrm{b}}$ \\
\hline Employee & $70(19.2)$ & $12.9 \pm 10.2$ & \\
\hline Worker & $133(36.4)$ & $12.8 \pm 10.6$ & \\
\hline Self-employed & $162(44.4)$ & $13.9 \pm 10.6$ & \\
\hline
\end{tabular}

${ }^{\text {a }}$ Post-hoc for differences between groups (different capital letters A, B and C in superscript show different groups 1, 2 and 3 respectively).

b One-way ANOVA.

${ }^{\mathrm{c}}$ Independent $t$-test.

${ }^{\mathrm{d}}$ Five were jobless.

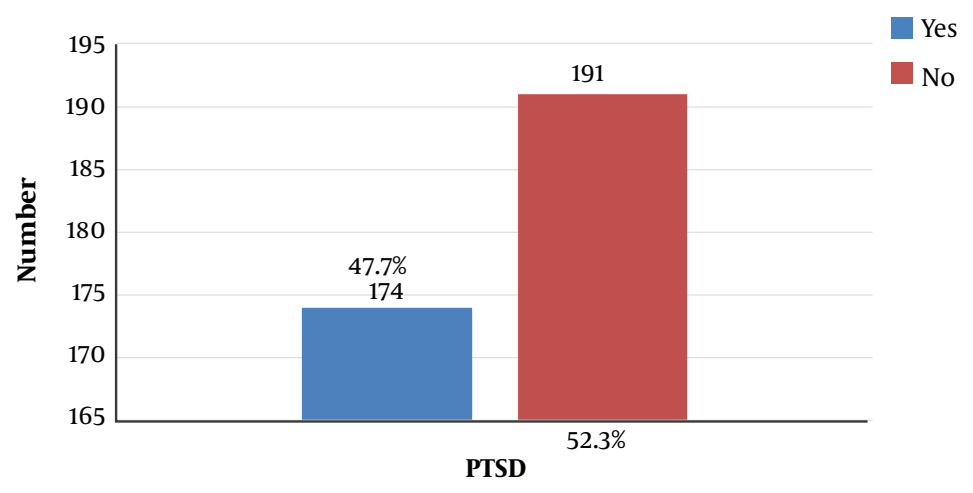

Figure 1. Prevalence of PTSD in the study participants according to the self-report questionnaire (PSS-I) 


\begin{tabular}{|c|c|c|c|}
\hline Midwifery Characteristic & No. (\%) & PTSD, Mean \pm SD & P-Value \\
\hline Gravida & & & $0.039^{b}$ \\
\hline 1 & $161(44.1)$ & $11.9 \pm 9.6$ & \\
\hline $2-3$ & $178(48.8)$ & $14.9 \pm 12.1$ & $0.040^{A, B}$ \\
\hline$>3$ & $26(7.1)$ & $15.2 \pm 8.5$ & \\
\hline Para & & & $0.027^{\mathrm{b}}$ \\
\hline 1 & $168(46.0)$ & $12.0 \pm 9.8$ & \\
\hline $2-3$ & $185(50.7)$ & $15.1 \pm 11.9$ & $0.02^{A, B}$ \\
\hline$>3$ & $12(3.3)$ & $13.1 \pm 5.9$ & \\
\hline Live children & & & $0.033^{\mathrm{b}}$ \\
\hline 1 & $167(45.8)$ & $12.03 \pm 9.8$ & \\
\hline $2-3$ & $186(50.9)$ & $15.9 \pm 12.5$ & $0.025^{A, B}$ \\
\hline$>3$ & $12(3.3)$ & $13.1 \pm 5.9$ & \\
\hline History of hospitalization & & & $0.880^{c}$ \\
\hline Yes & $7(2.6)$ & $13 \pm 8.4$ & \\
\hline No & $258(97.4)$ & $13.6 \pm 11.0$ & \\
\hline Place of childbirth & & & $0.204^{\mathrm{b}}$ \\
\hline Private hospital & $64(17.6)$ & $12.1 \pm 9.6$ & \\
\hline State hospital & $187(51.5)$ & $13.3 \pm 10.5$ & \\
\hline $\begin{array}{l}\text { Hospital covered by Social } \\
\text { Security Organization }\end{array}$ & $112(30.9)$ & $15.0 \pm 12.2$ & \\
\hline Birth attendant & & & $0.195^{b}$ \\
\hline Midwife & $140(38.4)$ & $12.7 \pm 11.3$ & \\
\hline Obstetrician & $184(50.4)$ & $14.1 \pm 10.4$ & \\
\hline Obstetric resident & $18(4.9)$ & $10.8 \pm 8.3$ & \\
\hline Midwifery student/intern & $23(6.3)$ & $17.1 \pm 14.8$ & \\
\hline Intended pregnancy in spouse & & & $0.003^{c}$ \\
\hline Yes & $274(75.1)$ & $12.6 \pm 10.7$ & \\
\hline No & $91(24.9)$ & $16.5 \pm 11.0$ & \\
\hline Intended pregnancy in woman & & & $0.002^{c}$ \\
\hline Yes & $268(73.4)$ & $12.5 \pm 10.9$ & \\
\hline No & $97(26.6)$ & $16.5 \pm 11.0$ & \\
\hline Desired route of delivery & & & $0.001^{\mathrm{c}}$ \\
\hline Vaginal & $246(67.6)$ & $12.1 \pm 10.6$ & \\
\hline Cesarean & $118(32.4)$ & $16.6 \pm 11.0$ & \\
\hline Type of recent delivery & & & $0.008^{b}$ \\
\hline Elective cesarean & $79(21.6)$ & $14.3 \pm 11.1$ & \\
\hline Repeated cesarean & $69(18.9)$ & $15.9 \pm 9.9$ & \\
\hline Vaginal without instrument & $212(58.1)$ & $12.3 \pm 10.8$ & \\
\hline Vacuum extraction & $5(1.4)$ & $25.0 \pm 17.1$ & $0.049^{C, D}$ \\
\hline $\begin{array}{l}\text { Number of times receiving } \\
\text { prenatal care }\end{array}$ & & & $0.810^{\mathrm{b}}$ \\
\hline No visit & $30(8.3)$ & $12.7 \pm 9.4$ & \\
\hline Less than six times & $41(11.3)$ & $13.0 \pm 11.1$ & \\
\hline $6-8$ times & $57(15.8)$ & $13.05 \pm 11.3)$ & \\
\hline More than eight times & $234(64.6)$ & $14.1 \pm 11.0$ & \\
\hline
\end{tabular}


Ahmadnejad Ret al.

\begin{tabular}{lcccc}
\hline Table 3. The Mean Score of PTSD and its Subdomains in Studied Women & & & \\
\hline Variables & Mean \pm SD & Median (Percentile 25 to 75) & Obtained Scores & Obtainable Scores \\
\hline Total score of PTSD & $13.6 \pm 10.9$ & $11(4-21)$ & $0-51$ & $0-51$ \\
Re-experiencing symptoms & $3.5 \pm 3.1$ & $3(1-5)$ & $0-12$ & $0-12$ \\
Avoidance symptoms & $5.1 \pm 4.9$ & $4(1-9)$ & $0-21$ & $0-21$ \\
Arousal symptoms & $4.9 \pm 4.30$ & $4(1-8)$ & $0-18$ & $0-18$ \\
\hline
\end{tabular}

section as the desired route of delivery (16.6 \pm 11.0$)$, and those undergoing instrumental vaginal delivery (25.0 \pm 17.1).

To investigate the sociodemographic and obstetrics predictors of PTSD, the variables of monthly income, gravidity, number of childbirth, intended pregnancy for woman and spouse, number of live children, desired route of delivery, and type of recent delivery, which had a relationship with the total score of PTSD with P-value $<0.1$, were entered into the multiple linear regression with backward stepwise selection. Further, the variables of income, number of live children, desired route of delivery, and type of recent delivery could predict $35 \%$ of the variance of PTSD. The total score of PTSD was higher in inadequate income compared to adequate income $(\beta=3.76 ; 95 \% \mathrm{CI}$ : 1.06 to 4.64; $\mathrm{P}=0.006)$, vaginal delivery compared to caesarian delivery ( $\beta=4.36$; 95\% CI: 0.03 to $6.68 ; \mathrm{P}<0.001)$ and vacuum extraction vaginal delivery compared to normal vaginal delivery ( $\beta=11.58$; $95 \% \mathrm{CI}: 2.39$ to $20.77 ; \mathrm{P}=0.014$ ) (Table 4).

\section{Discussion}

As mentioned earlier, the study evaluated the prevalence of PTSD and its sociodemographic and obstetrics predictors in 10 - 16 weeks of childbirth. The predictive variables of PTSD after childbirth were monthly income, number of live children, desired route of delivery, and type of recent delivery. Among the participants, $47.7 \%$ of women had PTSD, suggesting the high prevalence of PTSD following childbirth.

European studies, including those of England, Sweden, Germany, and Italy, reported a PTSD prevalence of 1 - 3\% (11, 24-27); it was also 5.9\% in Nigeria (12), 8 - 9\% in Canada and the US $(13,14)$, and up to $13 \%$ in France (15). In a study by Soderquist et al., the PTSD prevalence across time points after childbirth was reported 0.9 - 7.1\% (28). In Iran, two studies performed in Zahedan reported the PSTD prevalence of 17.2 - $32 \%(16,17)$. It was up to $36.7 \%$ in Bushehr $(18)$ and $39 \%$ in the Southern West Azerbaijan Province (19). The difference in the prevalence of PTSD probably goes back to different populations, geographical regions, and utilized research tools. The incidence of PTSD after childbirth can be affected by culture (4). The factors that seemingly play a role in this regard include family support, insurance coverage, maternity room facilities, spouse presence, and preand post-pregnancy training. However, there are some major factors that contribute to the high prevalence of PTSD in the Iranian setting, including unnecessary and irrelevant interventions during childbirth and lack of supportive care during labor, especially the absence of doula.

Wijma et al., found that PTSD symptoms were more frequent in primiparous women (27). Adewuya et al., also indicated that obstetrics variables, such as parity, can be a factor for PTSD, as it is more prevalent in nulliparous women compared with multiparous ones (12). The probable reason is the lack of adequate experience. According to the study by Vizeh et al., in Iran, the first pregnancy was among the most important obstetrics factors affecting PTSD incidence after childbirth (19). Inconsistent with the present study, the symptoms of PTSD were more frequent with the number of deliveries (women with 2 nd and 3rd deliveries). The reason behind the difference could be the heterogeneity of the study population or unpleasant experience in previous childbirths.

In line with the present study, Vizeh et al., in Iran reported insufficient monthly income as a predictive factor for PTSD following childbirth (19). In another research by Cohen et al., in Canada, a significant relationship was observed between the level of income and PTSD following childbirth (29). Soet et al., also concluded that low income could be a predictive factor in developing PTSD after childbirth (30). This relationship was also observed in the study by Modarres et al., in Iran (31). The probable reason for this relationship is the stress imposed on families after childbirth and the inability to afford costs.

In line with the present study, Rowlands et al., observed the maximum level of PTSD following forceps-assisted delivery (32). In the study by Maggioni et al., a significant relationship was reported between instrumental vaginal childbirth and PTSD (24). Adewuya et al., in a study in Nigeria, reported a significant relationship between instrumental vaginal delivery and PTSD (12).

No significant relationship was observed between vaginal delivery (even in non-instrumental cases) and PTSD in the study by Adewuya et al. (12). The reason for these differences could be the induction of labor and extreme pain caused by it, weak strategies to cope with pain (33), unmet 


\begin{tabular}{|c|c|c|c|}
\hline Variables & No. (\%) & $\beta(\mathbf{9 5} \% \mathbf{C I})$ & P-Value \\
\hline Income (reference: adequate) & $87(24.0)$ & - & \\
\hline Inadequate & $72(19.9)$ & $3.76(1.06-6.46)$ & 0.006 \\
\hline Relatively adequate & $203(56.1)$ & $-0.50(-3.14-2.14)$ & 0.708 \\
\hline Number of live children & - & $1.22(-0.04-2.48)$ & 0.057 \\
\hline Desired route of delivery (reference: cesarean) & $118(32.4)$ & - & \\
\hline Vaginal & $246(67.6)$ & $4.36(0.03-6.68)$ & $<0.001$ \\
\hline Type of recent delivery (reference: vaginal without instrument) & $212(58.1)$ & - & \\
\hline Repeated cesarean & $69(18.9)$ & $-0.15(-3.60-3.30)$ & 0.932 \\
\hline Vacuum extraction & $5(1.4)$ & $11.58(2.39-20.77)$ & 0.014 \\
\hline Elective cesarean & $79(21.6)$ & $-0.15(-3.01-2.710$ & 0.917 \\
\hline
\end{tabular}

${ }^{\text {a }}$ Adjusted $\mathrm{R}^{2}: 0.35$.

expectations of women during labor and childbirth (18), a distance between mother desire and reality of childbirth (34), high anxiety and tension in the maternity hospital, low support during labor and childbirth, poor interaction with care providers during labor and childbirth $(32,35,36)$, extreme motherhood complications after childbirth (31), and a traumatic experience of childbirth $(35,37)$.

In the present study, unintended pregnancy was significantly related to PTSD following childbirth. In the studies by Modares et al., (31) and Shaban et al., (17) in Iran, and Adewuya et al., in Nigeria (12), a significant relationship was found between unintended pregnancy and PTSD. In the study by Cohen et al., in Canada, no relationship was reported (29).

One of the limitations of the present study was its cross-sectional design, in which the relationships between sociodemographic and obstetrics characteristics and PTSD following childbirth did not accurately represent a causal relationship. Although most women refer to health centers in the postpartum period, it did not include those not referring to these centers for any reason, which somewhat lowered the generalizability of findings. Through medical records and self-report, depression and other psychiatric disorders were examined. Another limitation was the lack of simultaneous examination of depression and other psychiatric disorders by a questionnaire. The participation rate was $69 \%$ in the study. The number of instrumental deliveries was only five; therefore, its significant relationship with PTSD should be confirmed by further studies with larger populations. The present study acquired some merits of its own, including the sampling method and utilization of valid and reliable tools.

\subsection{Conclusion}

PTSD following childbirth was highly prevalent among the participating women. Given the high prevalence and adverse consequences, efficient interventions should be designed considering relevant sociodemographic and obstetrics variables to improve childbirth experience and prevent PTSD through promoting post-childbirth supports. It is recommended to screen and monitor mothers by healthcare providers (especially midwives) in childbirth follow-ups.

\section{Acknowledgments}

The authors wish to thank the study participants.

\section{Footnotes}

Authors' Contribution: Roya Ahmadnejad, Mojgan Mirghafourvand, Jamileh Malakouti, and Azizeh FarshbafKhalili, the study design; Roya Ahmadnejad, Mojgan Mirghafourvand, and Jamileh Malakouti, literature search; Roya Ahmadnejad, acquisition of data; Azizeh Farshbaf-Khalili, analysis of data; Roya Ahmadnejad, Mojgan Mirghafourvand, and Jamileh Malakouti, writing of the manuscript. All the authors contributed to manuscript drafting and read and approved the final version.

Conflict of Interests: The authors declared no conflicts of interest.

Ethical Approval: The study was approved by the Ethics Committee of Tabriz University of Medical Sciences (ethical code: IR.TBZMED.REC.1395.1293).

Funding/Support: The current study was financially supported by the Deputy of Research of Tabriz University of Medical Sciences.

Informed Consent: A signed, written informed consent was obtained from the participants. 


\section{References}

1. Gamble J, Creedy D, Moyle W, Webster J, McAllister M, Dickson P. Effectiveness of a counseling intervention after a traumatic childbirth: A randomized controlled trial. Birth. 2005;32(1):11-9. doi:10.1111/j.07307659.2005.00340.x. [PubMed: 15725200].

2. Gardner PS. Previous traumatic birth: An impetus for requested cesarean birth. J Perinat Educ. 2003;12(1):1-5. doi: 10.1624/105812403X106676. [PubMed: 17273325]. [PubMed Central: PMC1595139].

3. Beck CT, Driscoll J. Postpartum mood and anxiety disorders: A clinician's guide. Massachusetts, USA: Jones and Bartlett Publishers; 2006.

4. Paul TA. Prevalence of posttraumatic stress symptoms after childbirth: Does ethnicity have an impact? J Perinat Educ. 2008;17(3):17-26. doi: 10.1624/105812408X324534. [PubMed: 19436418]. [PubMed Central: PMC2517191].

5. Ahlund S, Clarke P, Hill J, Thalange NK. Post-traumatic stress symptoms in mothers of very low birth weight infants 2-3 years post-partum. Arch Womens Ment Health. 2009;12(4):261-4. doi: 10.1007/s00737-009-0067-4. [PubMed:19322638].

6. Muzik M, Bocknek EL, Broderick A, Richardson P, Rosenblum KL, Thelen $\mathrm{K}$, et al. Mother-infant bonding impairment across the first 6 months postpartum: The primacy of psychopathology in women with childhood abuse and neglect histories. Arch Womens Ment Health. 2013;16(1):29-38. doi: 10.1007/s00737-012-0312-0. [PubMed: 23064898]. [PubMed Central: PMC4040083].

7. Skari H, Skreden M, Malt UF, Dalholt M, Ostensen AB, Egeland T, et al. Comparative levels of psychological distress, stress symptoms, depression and anxiety after childbirth-A prospective populationbased study of mothers and fathers. BJOG. 2002;109(10):1154-63. doi: 10.1111/j.1471-0528.2002.00468.x. [PubMed: 12387470].

8. Gamble JA, Creedy DK, Webster J, Moyle W. A review of the literature on debriefing or non-directive counselling to prevent postpartum emotional distress. Midwifery. 2002;18(1):72-9. doi: 10.1054/midw.2001.0287. [PubMed: 11945055].

9. Goldbeck-Wood S. Post-traumatic stress disorder may follow childbirth. BMJ. 1996;313(7060):774. doi: 10.1136/bmj.313.7060.774. [PubMed: 8842066].

10. Harris R, Ayers S. What makes labour and birth traumatic? A survey of intrapartum 'hotspots'. Psychol Health. 2012;27(10):1166-77. doi: 10.1080/08870446.2011.649755. [PubMed: 22292475].

11. Ayers S, Pickering AD. Do women get posttraumatic stress disorder as a result of childbirth? A prospective study of incidence. Birth. 2001;28(2):111-8. doi: 10.1046/j.1523-536x.2001.00111.x. [PubMed: 11380382].

12. Adewuya AO, Ologun YA, Ibigbami OS. Post-traumatic stress disorder after childbirth in Nigerian women: Prevalence and risk factors. BJOG. 2006;113(3):284-8. doi: 10.1111/j.1471-0528.2006.00861.x. [PubMed: 16487199].

13. Beck CT, Gable RK, Sakala C, Declercq ER. Posttraumatic stress disorder in new mothers: Results from a two-stage U.S. national survey. Birth. 2011;38(3):216-27. doi: 10.1111/j.1523-536X.2011.00475.x. [PubMed: 21884230].

14. Verreault N, Da Costa D, Marchand A, Ireland K, Banack H, Dritsa M, et al. PTSD following childbirth: A prospective study of incidence and risk factors in Canadian women. J Psychosom Res. 2012;73(4):257-63. doi: 10.1016/j.jpsychores.2012.07.010. [PubMed: 22980529].

15. Montmasson H, Bertrand P, Perrotin F, El-Hage W. [Predictors of postpartum post-traumatic stress disorder in primiparous mothers]. J Gynecol Obstet Biol Reprod. 2012;41(6):553-60. French. doi: 10.1016/j.jgyn.2012.04.010. [PubMed: 22622194].

16. Firouzkouhi Moghadam M, Shamsi A, Hajizadeh Moro F. The prevalence of post-traumatic stress disorder among women with normal vaginal delivery in Zahedan city. Arch Psychiatry Psychother. 2015;17(1):15-9. doi:10.12740/app/37943.
17. Shaban Z, Dolatian M, Shams J, Alavi-Majd H, Mahmoodi Z, Sajjadi H. Post-traumatic stress disorder (PTSD) following childbirth: Prevalence and contributing factors. Iran Red Crescent Med J. 2013;15(3):17782. doi: 10.5812/ircmj.2312. [PubMed: 23983994]. [PubMed Central: PMC3745743].

18. Modarres M, Mirmolaie ST, Rahimikian F, Afrasiabie S. An epidemiologic assessment of post traumatic stress disorder following childbearing. Hayat. 2010;16(3-4):108.

19. Vizeh M, Kazemnejaz A, Afrasiabi S, Rouyhi M, Hassan M, Habibzadeh S. [Prevalance of post traumatic stress disorder after childbirth and its precipitating factors]. Hormozgan Medical Journal. 2012;16(4):30916. Persian.

20. Olde E, van der Hart O, Kleber RJ, van Son MJ, Wijnen HA, Pop VJ. Peritraumatic dissociation and emotions as predictors of PTSD symptoms following childbirth. J Trauma Dissociation. 2005;6(3):125-42. doi:10.1300/J229v06n03_06. [PubMed:16172085].

21. Boudou M, Sejourne N, Chabrol H. [Childbirth pain, perinatal dissociation and perinatal distress as predictors of posttraumatic stress symptoms]. Gynecol Obstet Fertil. 2007;35(11):1136-42. French. doi: 10.1016/j.gyobfe.2007.09.014. [PubMed: 17996476].

22. Foa EB, Cashman L, Jaycox L, Perry K. The validation of a self-report measure of posttraumatic stress disorder: The Posttraumatic diagnostic scale. Psychol Assess. 1997;9(4):445-51. doi: 10.1037/10403590.9.4.445.

23. Mirzamani M, Mohammadi MR, Besharat MA. Application of the PTSD symptoms scale (PSS) for Iranian PTSD patients. Med J Islam Repub Iran. 2006;19(4):345-8.

24. Maggioni C, Margola D, Filippi F. PTSD, risk factors, and expectations among women having a baby: A two-wave longitudinal study. J Psychosom Obstet Gynaecol. 2006;27(2):81-90. doi: 10.1080/01674820600712875. [PubMed:16808082].

25. Pantlen A, Rohde A. [Psychologic effects of traumatic live deliveries]. Zentralbl Gynakol. 2001;123(1):42-7. German. doi: 10.1055/s-2001-12025. [PubMed: 11385911].

26. Soderquist J, Wijma B, Thorbert G, Wijma K. Risk factors in preg nancy for post-traumatic stress and depression after childbirth. BJOG. 2009;116(5):672-80. doi: 10.1111/j.1471-0528.2008.02083.x. [PubMed: 19220236].

27. Wijma K, Soderquist J, Wijma B. Posttraumatic stress disorder after childbirth: A cross sectional study. J Anxiety Disord. 1997;11(6):587-97. doi: 10.1016/s0887-6185(97)00041-8. [PubMed: 9455721].

28. Soderquist J, Wijma B, Wijma K. The longitudinal course of posttraumatic stress after childbirth. J Psychosom Obstet Gynaecol. 2006;27(2):113-9. doi: 10.1080/01674820600712172. [PubMed: 16808086].

29. Cohen MM, Ansara D, Schei B, Stuckless N, Stewart DE. Posttraumatic stress disorder after pregnancy, labor, and delivery. $J$ Womens Health. 2004;13(3):315-24. doi: 10.1089/154099904323016473. [PubMed: 15130260].

30. Soet JE, Brack GA, Dilorio C. Prevalence and predictors of women's experience of psychological trauma during childbirth. Birth. 2003;30(1):36-46. doi: 10.1046/j.1523-536x.2003.00215.x. [PubMed: 12581038].

31. Modarres M, Afrasiabi S, Rahnama P, Montazeri A. Prevalence and risk factors of childbirth-related post-traumatic stress symptoms. BMC Pregnancy Childbirth. 2012;12:88. doi: 10.1186/1471-2393-12-88. [PubMed: 22938705]. [PubMed Central: PMC3512536].

32. Rowlands IJ, Redshaw M. Mode of birth and women's psychological and physical wellbeing in the postnatal period. BMC Pregnancy Childbirth. 2012;12:138. doi: 10.1186/1471-2393-12-138. [PubMed: 23190575]. [PubMed Central: PMC3533875].

33. Susan A, Harris R, Sawyer A, Parfitt Y, Ford E. Posttraumatic stress disorder after childbirth: Analysis of symptom presentation and sampling. J Affect Disord. 2009;119(1-3):200-4. doi: 10.1016/j.jad.2009.02.029. [PubMed: 19368975]. 
34. Stramrood CA, Paarlberg KM, Huis In 't Veld EM, Berger LW, Vingerhoets AJ, Schultz WC, et al. Posttraumatic stress following childbirth in homelike- and hospital settings. J Psychosom Obstet Gynaecol. 2011;32(2):88-97. doi: 10.3109/0167482X.2011.569801. [PubMed: 21557681].

35. Andersen LB, Melvaer LB, Videbech P, Lamont RF, Joergensen JS. Risk factors for developing post-traumatic stress disorder following childbirth: A systematic review. Acta Obstet Gynecol Scand. 2012;91(11):126172. doi: 10.1111/j.1600-0412.2012.01476.x. [PubMed: 22670573].

36. Garthus-Niegel S, von Soest T, Knoph C, Simonsen TB, Torgersen L,
Eberhard-Gran M. The influence of women's preferences and actual mode of delivery on post-traumatic stress symptoms following childbirth: A population-based, longitudinal study. BMC Pregnancy Childbirth. 2014;14:191. doi: 10.1186/1471-2393-14-191. [PubMed: 24898436]. [PubMed Central: PMC4053555].

37. Grekin R, O'Hara MW. Prevalence and risk factors of postpartum posttraumatic stress disorder: A meta-analysis. Clin Psychol Rev. 2014;34(5):389-401. doi: 10.1016/j.cpr.2014.05.003. [PubMed: 24952134]. 